\title{
DEPRESSÃO: UMA BREVE REVISÃO DOS FUNDAMENTOS BIOLÓGICOS E COGNITIVOS
}

Saint-Clair Bahls ${ }^{1}$

\begin{abstract}
RESUMO
É bastante conhecida a relevância da depressão no contexto clínico, costumando causar limitações e prejuízos significativos à pessoa, à família e à sociedade. Seu tratamento vem se ampliando e definindo áreas com recursos terapêuticos sempre mais específicos, tanto nos aspectos biológicos como nos psicológicos, que muitas vezes necessitam ser conjugados para permitir um resultado mais satisfatório. Os tratamentos existentes partem de pressupostos teóricos e também servem para o desenvolvimento de algumas hipóteses etiológicas da patologia. Neste artigo o autor faz uma revisão dos fundamentos biológico e cognitivo na depressão.
\end{abstract}

Palavras-chave: depressão, modelo biológico, modelo cognitivo.

\section{DEPRESSION: A BRIEF REVIEW OF THE BIOLOGICAL AND COGNITIVE FUNDAMENTS}

\section{ABSTRACT}

The relevance of depression in the clinical context is considerably well known for its ability to impose significant restrictions on and harm to individuals, families and society. The treatment of this condition has broadened and

${ }^{1}$ Professor da disciplina de Psicopatologia do curso de Psicologia da UFPR e Mestre em Psicologia da Infância e Adolescência pela UFPR. Praça Santos Andrade, 50 - $1^{\circ}$ andar - 80020-300 Curitiba - PR. E-mail: scbahls@uol.com.br. 
increasingly specific therapeutic resources have been defined, with regard to both its biological and psychological aspects, which often need to be dealt with together in order to achieve more satisfactory results. Existing treatments are based on theoretical suppositions and also contribute towards the development of some aetiological hypotheses regarding this illness. The author of the article reviews the biological and cognitive fundaments relating to depression.

Key-word: depression, biological model, cognitive model.

\section{INTRODUÇÃO}

A importância da depressão nos contextos de atenção à saúde e sua heterogeneidade na expressão clínica são presentemente bem conhecidas, além de representar uma patologia com alta e crescente prevalência na população geral (DSMIV, 1994; Talbott, Hales e Yudofsky, 1992). Segundo a OMS, nas próximas duas décadas haverá uma mudança nas necessidades de saúde da população mundial devido, em parte, ao fato de que doenças como depressão e cardiopatias estão, com rapidez, substituindo os problemas de doenças infecciosas e desnutrição. A sobrecarga das doenças mentais, entre elas a depressão, tem sido subestimada pelos levantamentos feitos, que costumam não avaliar a incapacitação causada pelas patologias, considerando somente sua mortalidade. Nesse cenário, muito se tem pesquisado na tentativa de compreender sua etiologia e aprimorar seu tratamento. Ainda desconhecida e em determinados aspectos controversa, a etiologia da depressão tem, para efeito de estudos, seus fatores divididos em: causas biológicas e psicossociais. Áreas estas que interagem intensamente entre si na expressão patoplástica da doença.

A proposição deste trabalho é enfocar os fundamentos biológicos e cognitivos dessa patologia. 


\section{MODELO BIOLÓGICO DA DEPRESSÃO}

As principais teorias relativas à base biológica da depressão situam-se nos estudos sobre neurotransmissores cerebrais e seus receptores, embora outras áreas também estejam sob investigação.

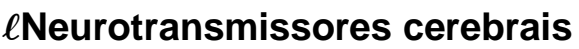

As monoaminas constituem-se na principal hipótese envolvendo os neurotransmissores cerebrais. Subdividem-se em catecolaminas: dopamina (DA) e noradrenalina (NE), e na indolamina: serotonina $(5 \mathrm{HT})$.

A hipótese das monoaminas baseia-se no conceito da deficiência das aminas biogênicas, particularmente NE, 5HT e DA, como a causa das depressões. A primeira hipótese aminérgica de Schildraut (1965) e Bunney e Davis (1965) foi denominada hipótese catecolaminérgica, pois propunha que a depressão se associava a um déficit das catecolaminas, principalmente a NE. Posteriormente surgiram a hipótese serotonérgica, de Van Praag e Korf (1971), que teve grande impulso com o desenvolvimento da classe de antidepressivos chamados Inibidores Seletivos de Recaptação da Serotonina (ISRS) e a hipótese dopaminérgica de Wilnner (1990), devido à implicação da DA nos fenômenos de recompensa cerebral, estando envolvida na fisiopatologia da anedonia, e de estudos demonstrando que o uso continuado de antidepressivos tricíclicos (ADT) aumenta a resposta comportamental à DA injetada no núcleo acumbens, que age como interface entre o sistema motor e o sistema límbico. Tal hipótese derivou inicialmente da compreensão advinda do conhecimento sobre o mecanismo de ação dos primeiros antidepressivos: tricíclicos e inibidores da monoaminoxidase (IMAO) que aumentam as concentrações das monoaminas nas fendas sinápticas cerebrais (Graeff e Brandão, 1993; Leonard, 1997; Stahl, 1998).

A reforçar a hipótese das monoaminas, houve outras evidências: a) drogas, como a reserpina, que depletam esses neu- 
rotransmissores são capazes de induzir depressão; b) precursores da 5HT: L-triptofano e 5-hidroxi-triptofano apresentam efeito antidepressivo leve; c) vários estudos relataram anormalidades nos metabólitos das aminas biogênicas, como o ácido 5-hidroxindol acético (5HIAA), o ácido homovanílico (HVA) e 3metoxi-4-hidroxiphenilglicol (MHPG) no sangue, urina e líquor de pacientes deprimidos; d) a redução da concentração de 5HT e seu principal metabólito 5HIAA ocorre no cérebro de vítimas de suicídio, alcançado de maneira violenta, e no líquor de pacientes deprimidos; e) a privação aguda de triptofano causa recidiva em $80 \%$ dos pacientes deprimidos tratados com sucesso com os antidepressivos da classe dos ISRS (Kaplan, Sadock e Grebb, 1994; Graeff e Brandão, 1993).

Apesar da relevância da hipótese das monoaminas na investigação da depressão, existe certa resistência para sua plena aceitação, especialmente devido ao fato de que todos os medicamentos antidepressivos aumentam, de imediato, as monoaminas em nível das fendas sinápticas, porém seu efeito clínico só ocorre algumas semanas depois (Oswald e col., 1972). Outras substâncias, como por exemplo a cocaína, também elevam os níveis das monoaminas, mas não apresentam efeito antidepressivo (Stahl, 1998). Do mesmo modo, nenhuma alteração nos índices de DA ou NE no líquor parece caracterizar pacientes deprimidos como um todo, e o nível reduzido de 5HIAA está mais relacionado a problemas de controle do impulso do que à depressão (Leonard, 1997).

O conhecimento atual da complexa inter-relação entre os sistemas neurotransmissores cerebrais restringiu as hipóteses de déficits de neurotransmissores nas fendas sinápticas a concepções simplistas e uma de suas conseqüências foi o deslocamento do foco das hipóteses biológicas da depressão para os receptores dos neurotransmissores. 


\section{$\ell$ Receptores}

O conhecimento dos receptores cerebrais evolui constantemente, sendo já identificados 4 subtipos de receptores noradrenérgicos, 7 subtipos de receptores serotoninérgicos e 5 subtipos de receptores dopaminérgicos. Alguns desses subtipos são ainda subclassificados em diferentes isoformas, tendo por base características farmacológicas e moleculares (Stahl, 1998).

O interesse a respeito da importância dos receptores na biologia da depressão derivou dos seguintes achados: a) a depleção de monoaminas provoca um aumento compensatório do número de receptores pós-sinápticos (o que, em psicofarmacologia, recebe a denominação de up-regulation); b) estudos post mortem, em cérebros de pacientes suicidas encontraram um acréscimo no número de receptores $5 \mathrm{HT}_{2}$ no córtex frontal; c) a ativação de alguns subtipos do mesmo receptor provoca efeitos diversos e até mesmo opostos, como no caso dos receptores $5 \mathrm{HT}_{2}$ e $5 \mathrm{HT}_{1 \mathrm{~A}}$ (Graeff e Brandão, 1993; Stahl, 1998; Willner, 1990). Este último achado levou Deakin e cols. (1991) a postular a hipótese da depressão com base no desequilíbrio de receptores serotonérgicos, sugerindo um déficit na neurotransmissão dos receptores $5 \mathrm{HT}_{1 \mathrm{~A}}$, e um excesso na neurotransmissão dos receptores $5 \mathrm{HT}_{2}$. Sabe-se que a distribuição cerebral desses receptores se faz de forma diversa no cérebro, havendo predomínio dos receptores $5 \mathrm{HT}_{2}$ na amígdala e dos receptores $5 \mathrm{HT}_{1 \mathrm{~A}}$ no hipocampo, ambos estruturas do sistema límbico (Graeff e Brandão, 1993).

Pressupondo anormalidades funcionais em alguns receptores, esta hipótese obteve um suporte significativo advindo das pesquisas com ligantes marcados radioativamente, evidenciando que, após o uso de antidepressivos por algumas semanas, ocorrem no cérebro de pacientes deprimidos alterações nos receptores noradrenérgicos, principalmente uma redução no número de receptores beta-adrenérgicos pós-sinápticos 
(down-regulation) (Graeff e Brandão, 1993; Leonard, 1997). Fato este encontrado após longo tratamento utilizando qualquer tipo de terapia antidepressiva somática.

Até hoje se conjetura da implicação dos receptores alfa2-adrenérgicos pré-sinápticos e dos receptores dopaminérgicos $\mathrm{D}_{1}$, estes últimos podendo se apresentar hipoativos na depressão, com a possibilidade da via dopaminérgica mesolímbica estar disfuncionante nesta patologia. Com menos evidência, mas também sob investigação, estão os receptores da acetilcolina, de alguns receptores opióides endógenos e os receptores $\mathrm{GABA}_{\mathrm{B}}$, entre outros (Kaplan, Sadock e Grebb, 1994; Talbott, Hales e Yudofsky, 1992).

A área da pesquisa sobre a implicação dos receptores deverá se aprofundar, identificando mais detalhadamente as características de cada subtipo de receptor e abre dois outros caminhos na elucidação dos fenômenos biológicos da depressão: I) o conhecimento do que ocorre no interior do neurônio pós-sináptico depois da estimulação do receptor e, II) através de técnicas moleculares, encontrar anormalidades na expressão genética de enzimas e receptores cerebrais.

\section{$\ell$ Considerações neuroanatômicas e rofisiológicas}

neu-

Em conseqüência dos estudos de neuroimagem estrutural e funcional é possível localizar certas áreas cerebrais predominantemente alteradas em pacientes com depressão maior. Encontra-se redução de volume e hipometabolismo nos lobos frontais, gânglios da base e estruturas mediais e temporais do cérebro, envolvendo essencialmente conexões entre os gânglios da base, os lobos frontais e o sistema límbico. O sistema límbico é intimamente ligado aos gânglios da base e ao hipotálamo lateral (Graeff e Brandão, 1993; Lafer, Renshaw e Sachs, 1998). Postula-se então, esquematicamente, que a disfunção no sistema límbico seja responsável pelas emoções alteradas; a disfunção nos gânglios da base envolva as altera- 
ções motoras; a disfunção no córtex pré-frontal anterolateral esquerdo responda pelo prejuízo cognitivo; a disfunção hipotalâmica seja a causa das alterações de sono, apetite, comportamento sexual, endocrinológicas, imunológicas e cronobiológicas na depressão (Kaplan, Sadock e Grebb, 1994). Chega-se assim à hipótese da heterogeneidade dos quadros depressivos, baseada na ruptura em diferentes regiões do circuito cerebral gânglios da base - tálamo-cortical (Lafer, Renshaw e Sachs, 1998).

Ainda quanto à questão biológica, convém lembrar as principais alterações somáticas da depressão, já bem definidas, envolvendo diversas anormalidades no sono verificadas através da polissonografia, a dessincronização nos ritmos circadianos e as perturbações neuroendocrinológicas, particularmente, nos eixos hipotálamo - hipófise - adrenal e hipotálamo - hipófise - tireóide (Graeff e Brandão, 1993; Kaplan, Sadock e Grebb, 1994; Talbott, Hales e Yudofsky, 1992).

\section{MODELO COGNITIVO DA DEPRESSÃO}

A teoria cognitiva postula que todos os afetos são secundários à cognição, sendo esta o modo peculiar de como vivenciamos e interpretamos os acontecimentos. O crescimento da importância dos componentes cognitivos na depressão ocorreu com os trabalhos de Beck (1963) postulando que a cognição é o fator determinante da doença, o transtorno cognitivo é elemento primário na patologia, e as construções negativistas do pensamento são o fato primeiro na cadeia sintomatológica. Bandura (1969) destaca que pessoas deprimidas apresentam expectativas de desempenho excessivamente elevadas, o que as conduz a experimentar pouco sucesso e muitos fracassos, induzindo-as a prestar atenção seletiva aos eventos negativos, tendendo à auto-avaliação negativa. Lembra ainda Bandura (1977), o ciclo vicioso dos deprimidos, com sua teoria do comportamento que influencia e é influenciado, uma vez que as pessoas depressivas, estando pessimistas, facilmente desper- 
tam rechaço ou rejeição o que intensifica sua autodesaprovação, tornando-as mais negativas e assim alimentando o ciclo doentio. Seligman (1977), com sua teoria do desamparo aprendido, colabora com os conceitos cognitivistas através da compreensão de que o aprendizado da impotência perante os acontecimentos, que se estabelece em determinadas pessoas no início da vida, é responsável pela representação cognitiva de fracasso existente nos pacientes deprimidos. Schereiber (1978) chega a afirmar que as distorções negativistas dos pacientes depressivos podem ser igualadas em importância aos sintomas básicos da depressão.

Beck (1976) teoriza a necessidade da existência de uma predisposição cognitiva para a depressão que se originaria nas experiências iniciais das pessoas, formando os conceitos ou esquemas negativistas sobre si mesmas e sobre a vida. Esses esquemas disfuncionais depressogênicos ficariam latentes, podendo se manifestar quando os indivíduos passassem por vivências semelhantes às iniciais, que foram responsáveis pela introjeção da atitude negativista. Guidano e Liotti (1983) propõem que os esquemas disfuncionais dos pacientes depressivos têm origem nas experiências de perdas ou desapontamentos durante a infância ou adolescência, causando distorções que moldam a percepção da realidade dentro de um espectro negativista. A experiência pessoal forma pressupostos cognitivos que estabelecem sistemas de valores e crenças que, por sua vez, dão sentido e previsão aos acontecimentos. Devido à forma e intensidade das experiências iniciais, alguns desses pressupostos podem ser disfuncionais, que por si só não causam a depressão mas, uma vez ativados, desencadeiam os chamados pensamentos negativos automáticos que interferem diretamente na interpretação de tudo que ocorre com os indivíduos. Portanto, na depressão há uma distorção patológica de um processo que existe em qualquer pessoa (Shinohara, 1998).

O modelo cognitivo propõe três conceitos clássicos para explicar o substrato psicológico da depressão: a tríade cogniti- 
va, os esquemas cognitivos disfuncionais e as distorções ou erros cognitivos.

A tríade cognitiva consiste no fato de o paciente apresentar uma visão negativa e persistente em relação a três aspectos fundamentais que são: sobre si mesmo, sobre o mundo e sobre o futuro. Através dessa interpretação errônea, o deprimido sente-se encurralado, envolvido por situações nas quais só podem ocorrer decepções, sofrimento, desamparo e desesperança. Beck e col. (1997) relacionam vários sintomas depressivos como conseqüência dessa visão negativista tríplice.

Os esquemas cognitivos dizem respeito à forma sistemática como a pessoa interpreta as situações adequando-as a suas referências vivenciais e também designam padrões estáveis que categorizam e avaliam as experiências. Na organização estrutural do paciente deprimido, esses padrões estáveis, que servem de base para transformar os dados em cognições, encontram-se disfuncionantes gerando percepções distorcidas da realidade que se encaixam aos esquemas depressogênicos previamente ativados (Goldrajch, 1996). O paciente perde grande parte do controle sobre seus pensamentos e não se acha em condições de utilizar outros esquemas que melhor se adaptem às situações. À medida que a depressão se intensifica mais automático se torna o pensamento. A pessoa pode vir a ser então inteiramente dominada pelo esquema disfuncionante, ficando a organização cognitiva autônoma e independente de fatores externos (Ito, 1997).

Os erros cognitivos representam as distorções que acontecem no processamento das informações, no sentido de adaptar a realidade aos esquemas negativistas. São erros sistemáticos que reforçam a crença do paciente em seus conceitos depressivos. Esses pensamentos ocorrem automaticamente, parecendo óbvios e naturais ao paciente. Segundo Burns (1980), os principais erros cognitivos são: absolutismo ou pensamento dicotômico, supergeneralização, abstração seletiva, 
desqualificação, inferência arbitrária, magnificação e minimização, racionalização emocional, sensação de obrigação, rotulações e personalização.

Beck e col. (1997) acreditam que a depressão se caracteriza por uma distorção da natureza humana. Segundo os autores, a organização cognitiva da pessoa deprimida sofre uma revolução cognitiva, que produz a inversão no modo de interpretar a realidade. Uma das características do paciente severamente deprimido é ser desatento em relação a informações ambientais, tendendo a perseverar em temas pessimistas, configurando uma organização cognitiva autônoma, que denominou de modelo cognitivo autônomo. Algumas depressões podem se apresentar relativamente não reativas, percorrendo um caminho inexorável, a despeito de influências ambientais favoráveis. Beck e col. (1997) reconhecem entretanto que o modelo cognitivo não aborda a questão da etiologia fundamental da depressão.

\section{COMENTÁRIOS}

Este trabalho demonstra a compreensão que se tem hoje no âmbito de dois dos modelos etiológicos da depressão. Tal abrangência porém não deve ser interpretada como definitiva e sim, como parcial e mutável, uma vez que novos conhecimentos certamente irão emergir e, se firmando, farão que essas noções sejam ampliadas e mesmo modificadas. A partir dos dados relatados, entende-se que a busca das raízes da depressão tem se aprofundado rapidamente. Entretanto, a despeito de já haver um montante considerável de informações, estas apresentam limitações e deficiências evidenciando que os aspectos ainda não conhecidos permanecem desafiando a ciência e os pesquisadores.

Torna-se imperativo que pesquisadores e cientistas desenvolvam e integrem tais hipóteses, categorizando-as de acordo com a sua importância etiopatogênica, reunindo os fato- 
res biológicos, psicológicos, como também os fatores socioambientais que compõem essa grande e importante área de investigação.

\section{REFERÊNCIAS BIBLIOGRÁFICAS}

Bandura A. (1969). Principles of behavior modification. New York: Holt, Rinehart \& Winston.

Bandura A. (1977). Social learning theory. Englewood Cliffs, N. J.: Prentice Hall.

Beck, A. T. (1963). Thinking and depression. 1: Idiosyncratic content and cognitive distortions. Arch Gen Psychiatry, 9, 324-333.

Beck, A. T. (1976). Cognitive therapy and the emotional disorders. New York: International Universities Press.

Beck, A. T, Rush, A. J, Shaw, F. B, Emery, E. (1997). Terapia cognitiva da depressão. Porto Alegre: Artes Médicas.

Bunney, W. E, Davis, J. M. (1965). Norepinephrine in depressive reactions. Arch. Gen. Psychiatry 13, 483-494.

Burns, D. D. (1980). Feeling good: the new mood therapy. New York: William Morrow.

Deakin, J. F. W; Guimarães, F. S.; Wang, M. \& Hensman, R. (1991). Experimental tests of the $5 \mathrm{HT}$ receptor imbalance theory of affective disturbance. Em M. Sandler; A. Coppen \& S. Harnett (orgs.), 5-Hydroxytriptamine in psychiatry. A spectrum of ideas (p. 143154). Oxford: Oxford University Press.

DSM-IV (1994). American Psychiatric Association, 4aㅡ ed. Washington: American Psychiatric Association.

Goldrajch D. F.E.L.I.Z. (1996). Uma estratégia cognitivo-comportamental para o manejo da depressão. J. Bras. Psiquiatria 45(12): 709-712.

Graeff, F. G. \& Brandão, M. L. (1993). Neurobiologia das doenças mentais. São Paulo: Lemos Editorial.

Guidano, V. F \& Liotti, G. (1983). Cognitive processes and emotional disorders. New York: Guilford Press.

Ito, L. M. (1997). Terapia cognitivo-comportamental para depressão. Em O. V. Forlenza \& O. P. Almeida (orgs.), Depressão e demência no idoso. São Paulo: Lemos Editorial. 
Kaplan, H. I.; Sadock, B. J. \& Grebb, J. A. (1994). Synopsis of Psychiatry. $7^{\text {th }}$ ed. Baltimore: Williams e Wilkins.

Lafer, B.; Renshaw, P. F. \& Sachs, G. S. (1998). Depressão maior e os gânglios da base. Em E. C. Miguel; S. L. Lauch \& J. F. Leckman (orgs.), Neuropsiquiatria dos gânglios da base. São Paulo: Lemos Editorial.

Leonard, B. E. (1997). The role of noradrenaline in depression: a review. J. Psychophatology 11(4): S39-S47.

Oswald. I.; Brezinova, L. E. \& Dunleavy, D. L. F. (1972). On the slowness of action of tricyclic antidepressant drugs. Br. J. Psychiatry, 120, 673-677.

Schildkraut, J. J. (1965). The catecholamine hypothesis of affective disorders: a review of supporting evidence. Am. J. Psychiatry, 122, 509-522.

Schreiber, M. T. (1998). Depressive cognitions. Am. J. Psychiatry, 135, 1.570.

Seligman, M. E. P. (1977). Desamparo - sobre depressão, desenvolvimento e morte. São Paulo: Hucitec-EDUSP.

Shinohara, H. (1998). Transtornos de humor. Em B. Rangé (org.), Psicoterapia comportamental e cognitiva de transtornos psiquiátri$\cos$ (p. 178-182). Campinas: Editorial Psy.

Stahl, S. M. (1998). Psicofarmacologia: bases neurocientíficas e aplicações clínicas. Rio de Janeiro: MEDSI - Editora Médica e Científica Ltda.

Talbott, J.; Hales, R. \& Yudofsky, S. (1992). Tratado de Psiquiatria. Porto Alegre: Artes Médicas.

Van Praag, H. M. \& Korf, J. (1971). Endogenous depression with and without disturbances of 5-hydroxytryptamine metabolism: a biochemical classification? Psychopharmacol. 19, 148-152.

Willner, P. (1990). Animal models of depression: on overview. Pharmacology and Therapeutics, 45, 425-455. 